\title{
Protective Effects of Aqueous Extract of Luehea divaricata against Behavioral and Oxidative Changes Induced by 3-Nitropropionic Acid in Rats
}

\author{
Aline Alves Courtes, ${ }^{1,2}$ Letícia Priscila Arantes, ${ }^{2}$ Rômulo Pillon Barcelos, ${ }^{2}$ \\ Ingrid Kich da Silva, ${ }^{2}$ Aline Augusti Boligon, ${ }^{2}$ Margareth Linde Athayde, ${ }^{2}$ \\ Robson Luiz Puntel, ${ }^{1}$ and Félix Alexandre Antunes Soares ${ }^{2}$ \\ ${ }^{1}$ Universidade Federal do Pampa (UNIPAMPA), Campus Uruguaiana, Uruguaiana, RS, Brazil \\ ${ }^{2}$ Departamento de Bioquímica e Biologia Molecular, Centro de Ciências Naturais e Exatas (CCNE), \\ Universidade Federal de Santa Maria (UFSM), Santa Maria, RS, Brazil \\ Correspondence should be addressed to Félix Alexandre Antunes Soares; felix@ufsm.br
}

Received 28 April 2015; Revised 14 August 2015; Accepted 15 September 2015

Academic Editor: Claudia Di Giacomo

Copyright (C) 2015 Aline Alves Courtes et al. This is an open access article distributed under the Creative Commons Attribution License, which permits unrestricted use, distribution, and reproduction in any medium, provided the original work is properly cited.

\begin{abstract}
Huntington's disease (HD) is an autosomal dominant neurodegenerative disease. Accordingly, 3-nitropropionic acid (3-NP) has been found to effectively produce HD-like symptoms. Luehea divaricata (L. divaricata), popularly known in Brazil as "açoitacavalo," may act as a neuroprotective agent in vitro and in vivo. We evaluated the hypothesis that the aqueous extract of $L$. divaricata could prevent behavioral and oxidative alterations induced by 3-NP in rats. 25 adult Wistar male rats were divided into 5 groups: (1) control, (2) L. divaricata (1000 mg/kg), (3) 3-NP, (4) L. divaricata $(500 \mathrm{mg} / \mathrm{kg})+3-\mathrm{NP}$, and (5) L. divaricata $(1000 \mathrm{mg} / \mathrm{kg})+$ 3-NP. Groups 2, 4, and 5 received $L$. divaricata via intragastric gavage daily for 10 days. Animals in groups 3, 4, and 5 received $20 \mathrm{mg} / \mathrm{kg} \mathrm{3-NP}$ daily from days 8-10. At day 10, parameters of locomotor activity and biochemical evaluations were performed. Indeed, rats treated with 3-NP showed decreased locomotor activity compared to controls. Additionally, 3-NP increased levels of reactive oxygen species and lipid peroxidation and decreased ratio of GSH/GSSG and acetylcholinesterase activity in cortex and/or striatum. Our results suggest that rats pretreated with $L$. divaricata prior to 3-NP treatment showed neuroprotective effects when compared to 3-NP treated controls, which may be due to its antioxidant properties.
\end{abstract}

\section{Introduction}

Huntington's disease (HD) is an autosomal dominant progressive neurodegenerative disorder, characterized by motor dysfunction, emotional disturbances, abnormal involuntary movements, dementia, and weight loss $[1,2]$. The neuropathological changes associated with these physical symptoms of HD include progressive neuronal degeneration and atrophy primarily affecting the striatum and cerebral cortex $[3,4]$. This neurodegenerative disorder is believed to be caused by an expanded trinucleotide CAG sequence in exon 1 of the Huntingtin gene (Htt), which encodes a stretch of glutamines in the Huntingtin protein [5]. Formation of Htt aggregates and alteration of overall gene expression profiles have also been reported in peripheral tissues of HD patients $[6,7]$. Compelling evidence also exists that mutant Huntingtin alters mitochondrial trafficking and function $[8,9]$.

HD-like symptoms may be induced experimentally in animal models through the administration of specific neurotoxins. 3-Nitropropionic acid (3-NP), a natural neurotoxin produced by several species of fungi (Aspergillus flavus and Astragalus arthrinium) and plants (Indigofera endecapylla) $[10,11]$, has been used successfully to induce HD-like symptoms in experimental animals $[12,13]$. The mechanism by which 3-NP induces neurotoxicity involves the irreversible inhibition of succinate dehydrogenase (SDH) $[14,15]$, which results in mitochondrial dysfunction, as evidenced by intracellular energy failure and oxidative stress $[16,17]$. 
3-NP-treated animals present with motor-behavioral disorders, including gait, an inability to balance over a narrow beam, deficits in foraging or exploratory behaviors and cognition, and increased anxiety and/or depression [15, 18]. Since it is generally recognized that 3-NP administration induces HD-like symptoms in animals with a phenotype similar to the inherited human disease, this model represents a valuable tool to evaluate the effect of novel therapies to treat HD [19].

Therapeutic strategies aimed at preventing or delaying neuronal degeneration represent a reasonable choice for the treatment of neurodegenerative diseases $[4,20,21]$. Accordingly, there is a growing interest in the use of natural antioxidants, including polyphenols found in medicinal and dietary plants that might prevent cell death and damage associated with the administration of various neurotoxins [13, 22-24].

The naturally occurring plant Luehea divaricata Mart. (Tiliaceae) (L. divaricata), popularly known in South America as "açoita-cavalo" $[25,26]$, contains numerous polyphenols. This plant has been used traditionally in folk medicine to treat dysentery, leucorrhea, rheumatism, blennorrhea, tumors, bronchitis, and skin lesions, among others [2628]. A phytochemical screening of $L$. divaricata leaves has revealed the presence of flavonoids, tannins, saponins, and mucilage. Additionally, alkaloids, fixed oils, anthocyanidins, carotenoids, and polysaccharides have also been found to be present in crude extracts of $L$. divaricata [28]. Although aqueous herbal extracts have attracted recent attention since they can be consumed in a daily basis as a decoction, few studies have evaluated the potential neuroprotective therapeutic effects of aqueous extracts, prepared as a tea, from leaves of $L$. divaricata. Previous studies have reported genotoxicity of the aqueous extract of $L$. divaricata leaves [29], a cytostatic effect of the methanolic extract of the leaves and antimutagenic activity of the aqueous extract of the bark [30]. In addition to these previous reports, the design of our research studies was also based on (1) previous data supporting the rational search for therapeutic strategies that either potentiate endogenous antioxidants or reduce oxidative stress generation in order to delay HD progression and (2) the knowledge that infusion of the leaves of L. divaricata in hot water releases high concentrations of polyphenols and flavonoids [31, 32]. Given the growing interest in natural antioxidants, especially polyphenols, present in medicinal and food plants, the putative antioxidant properties of $L$. divaricata aqueous extracts, the involvement of oxidative stress in neurodegenerative disorders (HD-like symptoms) induced by $3-\mathrm{NP}$, and the paucity of evidence concerning the potential protective effect of $L$. divaricata in experimental models of neurotoxicity/neuropathology, we evaluated the hypothesis that pretreatment with the aqueous extract of $L$. divaricata could prevent or attenuate the neurobehavioral sequelae induced by 3-NP administration in rats. Using high performance liquid chromatography (HPLC), we also characterized the phytochemical profile of the L. divaricata extract used in our study.

\section{Materials and Methods}

2.1. Chemicals. 3-Nitropropionic acid, thiobarbituric acid (TBA), malonaldehyde-bisdimethylacetal (MDA), and $2^{\prime}, 7^{\prime}$ dichlorofluorescein diacetate (DCFH-DA) were purchased from Sigma (St. Louis, MO, USA). All other reagents were obtained from local suppliers. Methanol, phosphoric acid, gallic acid, chlorogenic acid, caffeic acid, and rosmarinic acid were purchased from Merck (Darmstadt, Germany). Catechin, epicatechin, vitexin, rutin, quercetin, and luteolin were acquired from Sigma Chemical Co. (St. Louis, MO, USA). High performance liquid chromatography (HPLC-DAD) was performed with a Shimadzu Prominence Auto Sampler (SIL20A) HPLC system (Shimadzu, Kyoto, Japan), equipped with Shimadzu LC-20AT reciprocating pumps connected to a DGU 20A5 degasser with a CBM 20A integrator, SPD-M20A diode array detector, and LC solution 1.22 SP1 software.

2.2. Plant Material. The leaves of Luehea divaricata Mart. (family Tiliaceae) were used as the plant material and were collected in Santa Maria (Rio Grande do Sul, Brazil). The collection of the leaves of $L$. divaricata was carried out during the flowering period, which occurs in December. The taxonomic identification was confirmed by Department of Industrial Pharmacy of the Federal University of Santa Maria and registered under the number 225 in the Herbarium of the Industrial Pharmacy Department.

2.3. Preparation of the Extract. The leaves were dried for five days in a kiln with controlled temperature $\left(40^{\circ} \mathrm{C}\right)$. Aqueous extract was obtained by decoction for 10 minutes in distilled water at $100^{\circ} \mathrm{C}$. The resulting extract was then filtered by using a filter paper to remove particles in suspension. L. divaricata at $500 \mathrm{mg} / \mathrm{kg}$ and $1000 \mathrm{mg} / \mathrm{kg}$ were chosen to treat experimental animals based on previous pilot experiment, which demonstrated none toxic effect of the extract. Of particular importance, literature data are not conclusive regarding $L$. divaricata therapeutic dose in animal experiments [27].

2.4. Quantification of Compounds by HPLC-DAD. The phenolic compound profiles were determined according to the procedure proposed by Filho et al. [33], with slight modifications. The aqueous extract of Luehea divaricata $(25 \mathrm{mg} / \mathrm{mL})$ was analysed using a reversed phase carried out under gradient conditions using Phenomenex $\mathrm{C}_{18}$ column $(4.6 \mathrm{~mm} \times$ $250 \mathrm{~mm}$ ) packed with $5 \mu \mathrm{m}$ diameter particles. Spectral data were recorded from 200 to $700 \mathrm{~nm}$ during the whole run. The mobile phase was composed of solvent (A) water: phosphoric acid $(99: 1, \mathrm{v} / \mathrm{v})$ and (B) methanol : water $(95: 5, \mathrm{v} / \mathrm{v})$ and the composition gradient was as follows: $0-5 \% \mathrm{~B}$ in $10 \mathrm{~min}, 5-$ $20 \% \mathrm{~B}$ in $35 \mathrm{~min}, 20-50 \% \mathrm{~B}$ in $50 \mathrm{~min}$, and $50-100 \% \mathrm{~B}$ in $70 \mathrm{~min}$. A flow rate of $0.6 \mathrm{~mL} / \mathrm{min}$ was used, $40 \mu \mathrm{L}$ of sample was injected, and the wavelengths were $271 \mathrm{~nm}$ for gallic acid, $280 \mathrm{~nm}$ for catechin and epicatechin, $327 \mathrm{~nm}$ for chlorogenic, caffeic, and rosmarinic acids, and $366 \mathrm{~nm}$ for luteolin, vitexin, quercetin, and rutin. Samples and mobile phases were filtered through a $0.45 \mu \mathrm{m}$ membrane filter (Millipore) prior to HPLC injection. Phenolic compounds were identified and quantified by comparing their retention time and UV-visible 
spectral data to known previously injected standards. Stock solutions of standards references were prepared in the HPLC mobile phase at a concentration range of $0.030-0.450 \mathrm{mg} / \mathrm{mL}$. The chromatography peaks were confirmed by comparing its retention time with those of reference standards and by DAD spectra (200 to $600 \mathrm{~nm}$ ). Calibration curve for gallic acid is $Y=12609 x+1187.3(r=0.9999)$; catechin is $Y=11952 x+$ $1308.5(r=0.9997)$; epicatechin is $Y=11845 x+1327.9$ $(r=0.9999)$; chlorogenic acid is $Y=11695 x+1263.7$ $(r=0.9994)$; caffeic acid is $Y=12704 x+1326.8(r=0.9998)$; rosmarinic acid is $Y=12549 x+1243.6(r=0.9995)$; vitexin is $Y=11895 x+1306.7(r=0.9998)$; luteolin is $Y=$ $13475 x+1279.1(r=0.9999)$; rutin is $Y=12569 x+1307.5$ $(r=0.9997)$; and quercetin is $Y=12409 x+1187.3(r=$ 0.9995). All chromatography operations were carried out at ambient temperature and in triplicate. The limit of detection (LOD) and limit of quantification (LOQ) were calculated based on the standard deviation of the responses and the slope using three independent analytical curves. LOD and LOQ were calculated as 3.3 and $10 \sigma / S$, respectively, where $\sigma$ is the standard deviation of the response and $S$ is the slope of the calibration curve [33].

2.5. Animals. All experiments were conducted using male adult Wistar rats (200-250 g) from our own breeding colony. Animals were housed in cages (5 rats per cage) with free access to food and water. They were kept in a $12 \mathrm{~h}$ light $/ 12 \mathrm{~h}$ dark cycle, with lights on at 7:00 a.m., in an air-conditioned room $\left(22 \pm 2^{\circ} \mathrm{C}\right)$. Commercial diet and tap water were supplied ad libitum. Animal care and all experimental procedures were conducted in compliance with the Committee on Care and Use of Experimental Animal Resources (CEUA/UFSM 102/2014). All efforts were made to minimize the number of animals used and their suffering.

2.6. 3-NP Induced Neurotoxicity. 3-NP was diluted in buffered saline ( $\mathrm{pH} 7.4$ ) and administered intraperitoneally (i.p.) at a dose of $20 \mathrm{mg} / \mathrm{kg}$ once a day, for a period of 3 days to induce HD-like symptoms. The 3-NP dose was chosen based in a preliminary study in which were observed biochemistry alterations characteristic of 3-NP neurotoxicity, but with some modifications [13].

2.7. Treatment. Twenty-five animals were divided into five groups with five animals each.

Group 1 (control) received pretreatment with distilled water for 7 days, by intragastric gavage.

Group 2 (L. divaricata) received daily, during 7 days, the aqueous extract at a concentration of $1000 \mathrm{mg} / \mathrm{kg}$ via intragastric gavage.

Group 3 (3-NP) received pretreatment with distilled water for 7 days, by intragastric gavage.

Group 4 (L. divaricata $+3-\mathrm{NP}$ ) received daily, during 7 days, the aqueous extract at a concentration of $500 \mathrm{mg} / \mathrm{kg}$ via intragastric gavage.

Group 5 (L. divaricata $+3-\mathrm{NP}$ ) received daily, during 7 days, the aqueous extract at a concentration of $1000 \mathrm{mg} / \mathrm{kg}$ via intragastric gavage.
On the eighth day, groups 3, 4, and 5 received the administration of $20 \mathrm{mg} / \mathrm{kg} 3-\mathrm{NP}$ via i.p. [13] for 3 consecutive days, while groups 1 and 2 received only saline (also via i.p.). During the administration of 3-NP, rats continued to receive the aqueous extract by gavage, which results in 10 days of treatment.

All the behavioral parameters were observed on day 10 , $3 \mathrm{~h}$ after the last 3-NP administration. At the end of the behavioral analyses, rats were euthanized, in a total of $6 \mathrm{~h}$ after the last 3-NP administration, the brain was removed, and the cortex and the striatum were dissected. A portion of the cortex and striatum were homogenized $(1: 10)$ in $10 \mathrm{mM}$ Tris-buffer $(\mathrm{pH} 7.4)$ and centrifuged at $2.500 \mathrm{rpm}$ for $12 \mathrm{~min}$. The low-speed supernatant fraction obtained was used for biochemical analyses.

\subsection{Behavioral Evaluations}

2.8.1. Open Field. Animals were individually placed at the center of the open field apparatus $(45 \mathrm{~cm} \times 45 \mathrm{~cm} \times 30 \mathrm{~cm}$, divided into 9 squares). Spontaneous ambulation (number of segments crossed with the four paws) and exploratory activity (expressed by the number of rearings on the hind limbs) were recorded for $5 \mathrm{~min}$ [34].

2.8.2. Rotarod Task. The integrity of motor system was evaluated using the Rotarod test. Briefly, the Rotarod apparatus consists of a rod $30 \mathrm{~cm}$ long and $3 \mathrm{~cm}$ in diameter that is subdivided into three compartments by discs from $24 \mathrm{~cm}$ in diameter. The rod rotates at a constant speed of $10 \mathrm{rpm}$. The animals were given a prior training session before the initialization of any therapy to acclimate them to Rotarod apparatus. The latency for first fall and number of falls from the rod were noted. The cut-off time was $120 \mathrm{~s}$ [35].

\subsection{Biochemical Analysis}

2.9.1. Estimation of ROS Formation. $2^{\prime}-7^{\prime}$-Dichlorofluorescein (DCF) levels were determined as an index of the reactive species production by the cellular components [36]. Aliquots $(20 \mu \mathrm{L})$ of homogenate of cortex and striatum were added to a medium containing $2,460 \mu \mathrm{L}$ Tris- $\mathrm{HCl}$ buffer $(10 \mathrm{mM}$, pH 7.4) and $20 \mu \mathrm{L} 2^{\prime}-7^{\prime}$-dichlorofluorescein diacetate DCFHDA $(0.1 \mathrm{mM})$. After DCFH-DA addition, the medium was incubated in the dark for $1 \mathrm{~h}$ until fluorescence measurement procedure (excitation at $488 \mathrm{~nm}$ and emission at $525 \mathrm{~nm}$, and both slit widths used were at $1.5 \mathrm{~nm}$ ). DCF levels were determined using a standard curve of DCF, and results were corrected by the protein content.

\subsubsection{Thiobarbituric Acid Reactive Substances (TBARS) Levels} Determination. Lipid peroxidation was determined by measuring thiobarbituric acid reactive substances (TBARS) as described by [37]. An aliquot $(200 \mu \mathrm{L})$ of homogenate of brain structures (cortex and striatum) was mixed with $500 \mu \mathrm{L}$ thiobarbituric acid (TBA, $0.6 \%$ ), $200 \mu \mathrm{L}$ sodium dodecyl sulphate (SDS, $8.1 \%$ ), and $500 \mu \mathrm{L}$ acetic acid (500 mM, pH 3.4) and incubated at $100^{\circ} \mathrm{C}$ for $1 \mathrm{~h}$. TBARS levels were measured at 
$532 \mathrm{~nm}$ using a standard curve of malondialdehyde (MDA), and the results were reported as nmol MDA/mg protein.

2.9.3. Fluorometric Assay of Reduced (GSH) and Oxidized Glutathione (GSSG). For measurement of GSH and GSSG levels we used the method previously described by [38]. Briefly, $400 \mu \mathrm{L}$ of homogenate each of brain structures (cortex and striatum) was mixed to $200 \mu \mathrm{L}$ trichloroacetic acid (TCA, 13\%). Resulting mixtures were centrifuged at $4^{\circ} \mathrm{C}$ at $13,000 \mathrm{rpm}$ for $10 \mathrm{~min}$. For GSH measurement, $100 \mu \mathrm{L}$ of the supernatant was diluted in $1,800 \mu \mathrm{L}$ of phosphate-EDTA buffer (sodium phosphate $100 \mathrm{mM}$ and EDTA $5 \mathrm{mM}, \mathrm{pH}$ 8) and $100 \mu \mathrm{L}$ of $\mathrm{O}$-phthalaldehyde (OPT $1 \mathrm{mg} / \mathrm{mL}$ ). The mixtures were incubated at room temperature for $15 \mathrm{~min}$ and their fluorescent signals were recorded in the RF-5301 PC Shimadzu spectrofluorometer (Kyoto, Japan) at $420 \mathrm{~nm}$ of emission and $350 \mathrm{~nm}$ of excitation wavelengths.

For measurement of GSSG levels, a $250 \mu \mathrm{L}$ of the supernatant was incubated at room temperature with $100 \mu \mathrm{L}$ of N-ethylmaleimide (NEM $0.04 \mathrm{M}$ ) for $30 \mathrm{~min}$ at room temperature, and after that $140 \mu \mathrm{L}$ of the mixture was added to $1,760 \mu \mathrm{L}$ of sodium hydroxide $(\mathrm{NaOH}, 0.1 \mathrm{~N})$ buffer, following the addition of $100 \mu \mathrm{L} \mathrm{OPT}$, and incubated for $15 \mathrm{~min}$, using the procedure outlined above for GSH assay. Collectively, data were expressed as a ratio among reduced (GSH) and oxidized (GSSG) glutathione (GSH/GSSG).

2.9.4. Acetylcholinesterase (AChE) Activity. AChE activity was determined according to the method of [38], with some modifications. In brief, we used $875 \mu \mathrm{L}$ of the reaction mixture, containing potassium phosphate buffer $(0.1 \mathrm{M}, \mathrm{pH}$ 8), $50 \mu \mathrm{L}$ 5,5-dithiobis-2-nitrobenzoic acid (DTNB, $10 \mathrm{mM}$ ), $25 \mu \mathrm{L}$ of homogenate of cortex and striatum, and $50 \mu \mathrm{L}$ acetylthiocholine iodide $(9 \mathrm{mM})$. Change in absorbance was monitored for $2 \mathrm{~min}$ at $412 \mathrm{~nm}$.

2.9.5. Protein Determination. The protein content was determined as described previously [39], using bovine serum albumin (BSA) as standard.

2.10. Statistical Analysis. Statistical analysis was performed using one-way analysis of variance (ANOVA), followed by multiple comparison test of Newman-Keuls when appropriate. Data are expressed as means \pm SEM. Values of $p<0.05$ were considered significant. Differences between groups of HPLC were assessed by an analysis of variance model and Tukey's test. The level of significance for the analyses was set to $p<0.05$.

\section{Results}

3.1. HPLC Analysis. HPLC fingerprinting of Luehea divaricata aqueous extract revealed the presence of gallic acid $\left(t_{R}=9.85 \mathrm{~min}\right.$; peak 1$)$, catechin $\left(t_{R}=14.93 \mathrm{~min}\right.$, peak 2$)$, chlorogenic acid $\left(t_{R}=21.07 \mathrm{~min}\right.$; peak 3$)$, caffeic acid $\left(t_{R}\right.$ $=25.19 \mathrm{~min}$; peak 4$)$, epicatechin $\left(t_{R}=31.84 \mathrm{~min}\right.$; peak 5$)$, vitexin $\left(t_{R}=41.08 \mathrm{~min}\right.$; peak 6$)$, rosmarinic acid $\left(t_{R}=\right.$ 45.98 min; peak 7$)$, rutin $\left(t_{R}=48.37 \mathrm{~min}\right.$; peak 8$)$, quercetin
TABLE 1: Composition of Luehea divaricata aqueous extract.

\begin{tabular}{lcccc}
\hline \multirow{2}{*}{ Compounds } & \multicolumn{2}{c}{$\begin{array}{c}\text { Luehea divaricata } \\
\mathrm{mg} / \mathrm{g}\end{array}$} & $\begin{array}{c}\mathrm{LOD} \\
\mathrm{g}\end{array}$ & $\mathrm{LOQ}$ \\
\hline Gallic acid & $3.51 \pm 0.02^{\mathrm{a}}$ & 0.35 & 0.025 & $\mu \mathrm{g} / \mathrm{mL}$ \\
Catechin & $6.27 \pm 0.01^{\mathrm{b}}$ & 0.62 & 0.018 & 0.078 \\
Chlorogenic acid & $3.42 \pm 0.01^{\mathrm{a}}$ & 0.34 & 0.009 & 0.031 \\
Caffeic acid & $1.68 \pm 0.03^{\mathrm{c}}$ & 0.16 & 0.011 & 0.037 \\
Epicatechin & $8.31 \pm 0.01^{\mathrm{d}}$ & 0.83 & 0.024 & 0.071 \\
Vitexin & $15.07 \pm 0.01^{\mathrm{e}}$ & 1.50 & 0.013 & 0.049 \\
Rosmarinic acid & $6.12 \pm 0.02^{\mathrm{b}}$ & 0.61 & 0.029 & 0.091 \\
Rutin & $1.59 \pm 0.01^{\mathrm{c}}$ & 0.15 & 0.010 & 0.034 \\
Quercetin & $10.76 \pm 0.03^{\mathrm{f}}$ & 1.07 & 0.030 & 0.096 \\
Luteolin & $19.45 \pm 0.01^{\mathrm{g}}$ & 1.94 & 0.007 & 0.023 \\
\hline
\end{tabular}

Results are expressed as mean \pm standard error of mean (SEM) of three determinations. Averages followed by different letters differ by Tukey test at $p<0.05$.

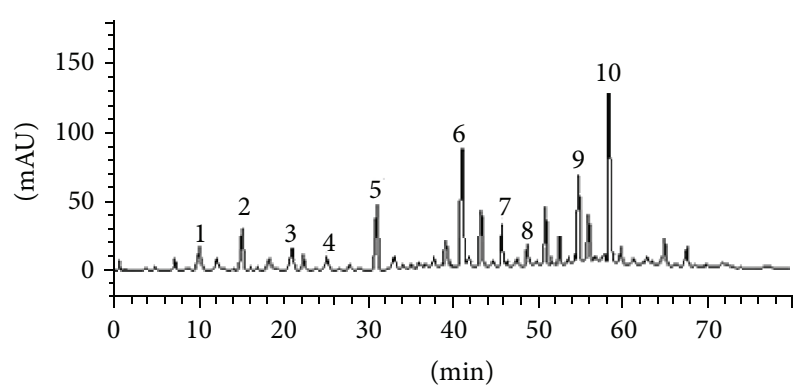

FIGURE 1: Representative high performance liquid chromatography profile of Luehea divaricata aqueous extract. Gallic acid (peak 1), catechin (peak 2), chlorogenic acid (peak 3), caffeic acid (peak 4), epicatechin (peak 5), vitexin (peak 6), rosmarinic acid (peak7), rutin (peak 8), quercetin (peak 9), and luteolin (peak 10).

$\left(t_{R}=54.23 \mathrm{~min}\right.$; peak 9$)$, and luteolin $\left(t_{R}=58.11 \mathrm{~min}\right.$; peak 10$)$ (Figure 1 and Table 1).

3.2. Behavioral Alterations. Locomotor and exploratory activity in the open field test were significantly decreased following 3-NP administration (Figures 2(a) and 2(b), resp.). Treatment with L. divaricata (500 or $1000 \mathrm{mg} / \mathrm{kg}$ ) partially restored both behavioral parameters to control levels ( $p<0.05$, Figures 2(a) and 2(b)). Additionally, statistical analysis of motor performance in the Rotarod task demonstrated that 3-NP caused a significant reduction of latency to remain on the rotating rod and significantly increased the number of falls off the rod when compared to the control group. Treatment with $L$. divaricata (500 or $1000 \mathrm{mg} / \mathrm{kg}$ ) was found to completely and significantly attenuate 3-NP-induced changes in Rotarod latency scores and partially restore the animal's ability to remain on the Rotarod ( $p<0.05$, Figures 3(a) and 3(b)). Surprisingly, L. divaricata (500 or $1000 \mathrm{mg} / \mathrm{kg}$ ) treatment was found to significantly decrease the latency to the first fall, when compared to control group ( $p<0.05$, Figure 3(a)). 


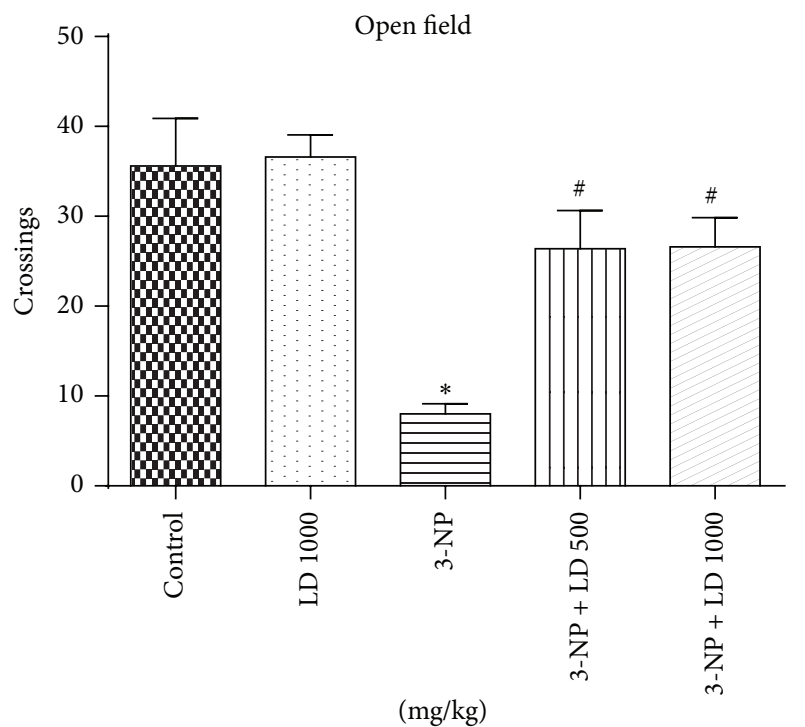

(a)

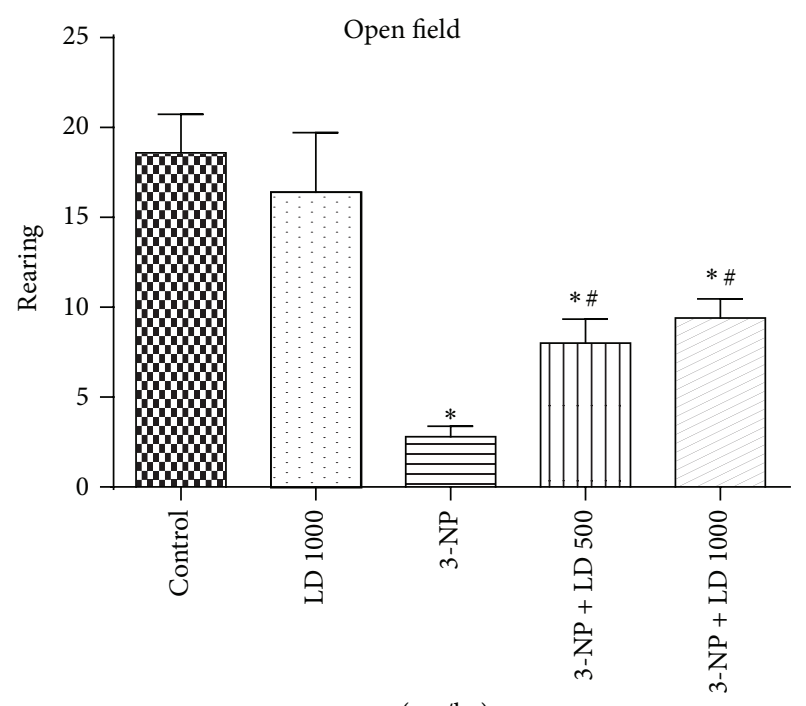

$(\mathrm{mg} / \mathrm{kg})$

(b)

Figure 2: Effects of 3-NP (20 mg/kg, i.p., 3 days) and/or Luehea divaricata (LD) (500 and $1000 \mathrm{mg} / \mathrm{kg}$, by gavage, 10 days) on locomotor and exploratory activities. (a) Number of crossings in the open field; (b) number of rearings in the open field. Each bar represents means \pm SEM $(n=5) . *$ indicates statistic difference from control group and \# indicates statistic difference from 3-NP group by one-way ANOVA, followed by Newman Keuls test for post hoc comparison $(p<0.05)$.

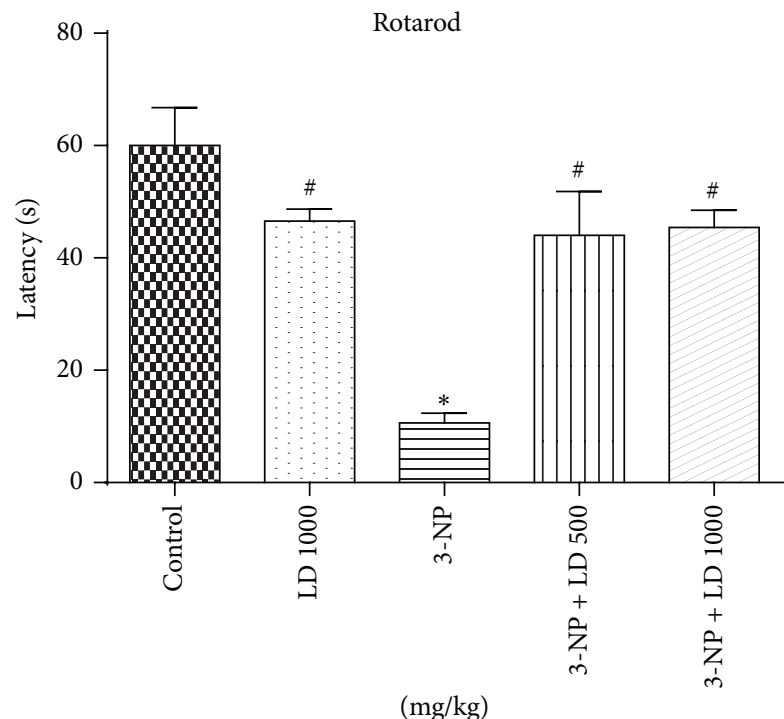

(a)

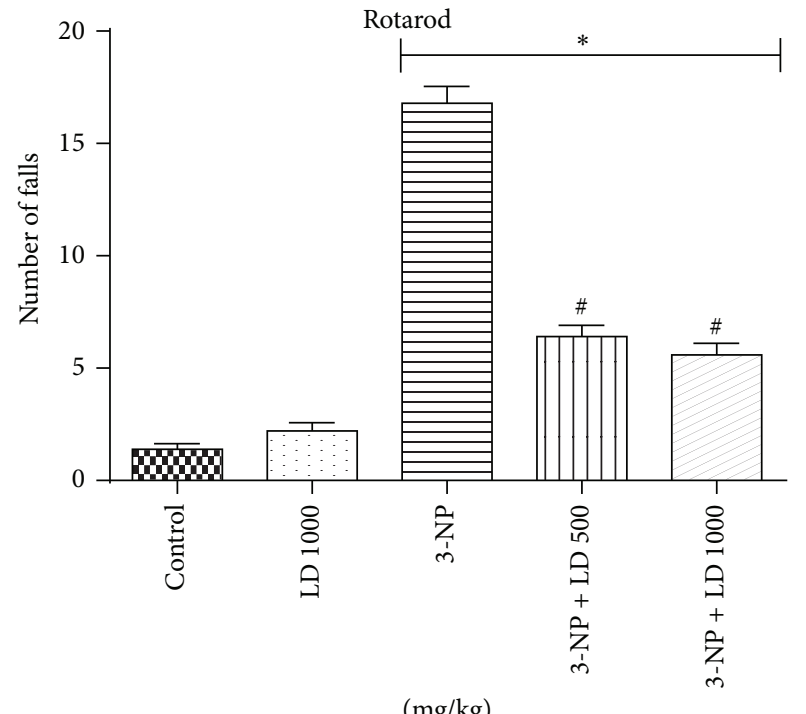

$(\mathrm{mg} / \mathrm{kg})$

(b)

FIGURE 3: Effects of 3-NP (20 mg/kg, i.p., 3 days) and/or Luehea divaricata (LD) (500 and $1000 \mathrm{mg} / \mathrm{kg}$, by gavage, 10 days) on latency to the first fall (a) and number of falls (b) in motor performance of rats in the Rotarod task. Each bar represents means \pm SEM $(n=5)$. * indicates statistic difference from control group and \# indicates statistic difference from 3-NP group by one-way ANOVA, followed by Newman Keuls post hoc test $(p<0.05)$.

3.3. Biochemical Alterations. Animals treated with 3-NP showed a significant increase $(p<0.05)$ in DCF oxidation, an index of reactive oxygen species (ROS) formation, in both cortex and striatum, when compared with control group (Figures 4(a) and 4(b), resp.). L. divaricata treatment completely prevented ROS formation in the cortex $(p<0.05$, Figure 4(a)), while its effect on striatum was partial (Figure 4(b)). In addition, 3-NP administration significantly increased lipid peroxidation, measured by TBARS production, in the cortex when compared to the control group $(p<0.05$, Figure 5(a)). L. divaricata treatment, at both concentrations, completely prevented the 3-NP-induced 


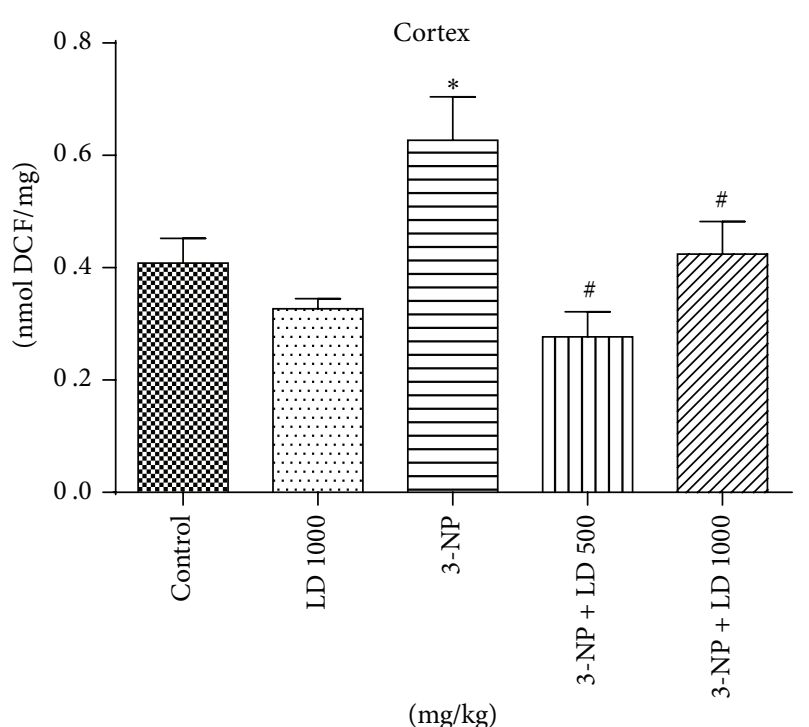

(a)

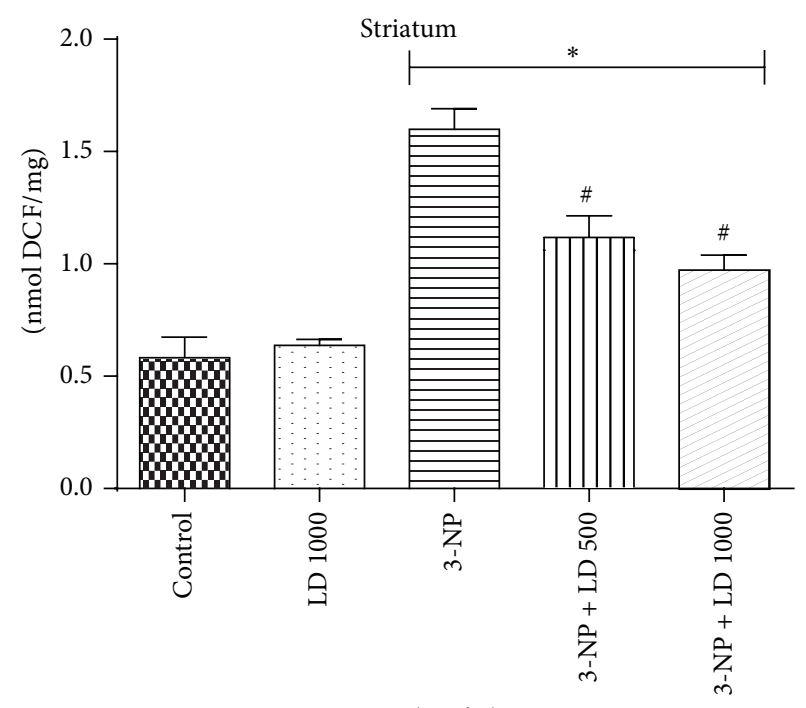

$(\mathrm{mg} / \mathrm{kg})$

(b)

Figure 4: Effects of 3-NP (20 mg/kg, i.p., 3 days) and/or Luehea divaricata (LD) (500 and $1000 \mathrm{mg} / \mathrm{kg}$, by gavage, 10 days) on ROS formation in cortex (a) and striatum (b) of treated rats. Data are expressed as nmol DCF/mg. Each bar represents means \pm SEM $(n=5)$. $*$ indicates statistic difference from control group and \# indicates statistic difference from 3-NP group by one-way ANOVA, followed by Newman Keuls post hoc test $(p<0.05)$.

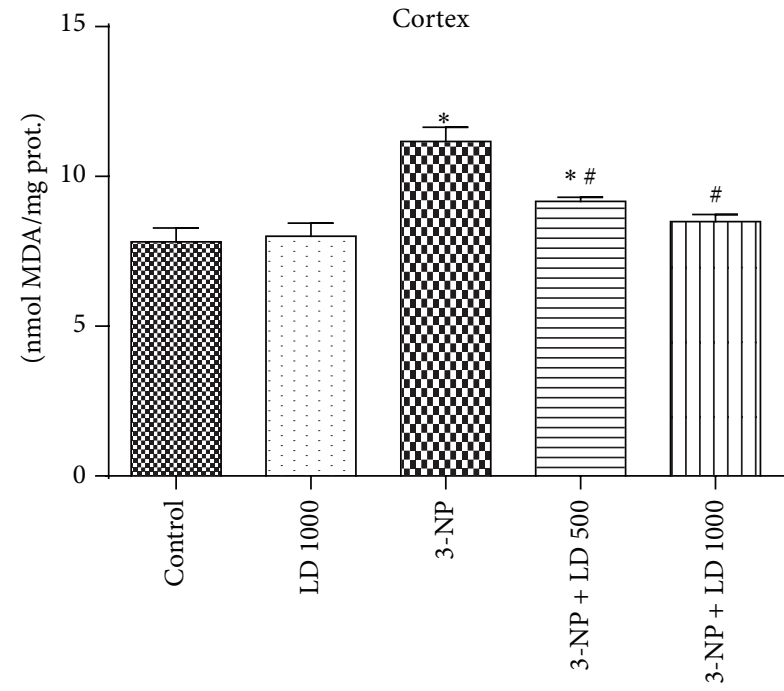

$(\mathrm{mg} / \mathrm{kg})$

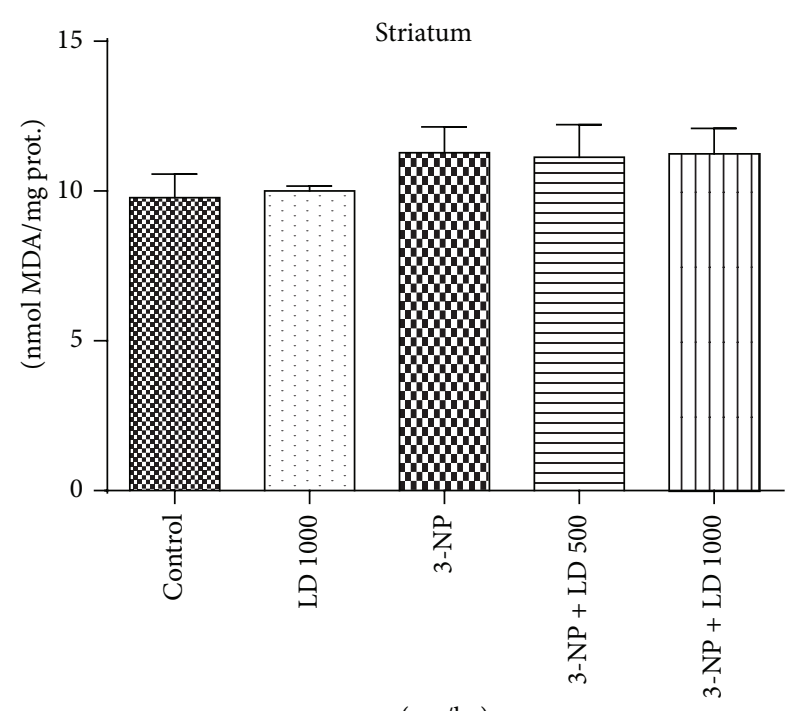

$(\mathrm{mg} / \mathrm{kg})$

(a)

(b)

FIGURE 5: Effects of 3-NP (20 mg/kg, i.p., 3 days) and/or Luehea divaricata (LD) (500 and $1000 \mathrm{mg} / \mathrm{kg}$, by gavage, 10 days) on TBARS levels in cortex (a) and striatum (b). Data are expressed as nmol MDA/mg of tissue. Each bar represents means \pm SEM $(n=5)$. * indicates statistic difference from control group and \# indicates statistic difference from 3-NP group by one-way ANOVA, followed by Newman Keuls post hoc test $(p<0.05)$.

increase in TBARS levels in the cortex $(p<0.05)$. Striatal TBARS levels were not modified by 3-NP administration and/or L. divaricata treatment (Figure 5(b)).

Administration of 3-NP also caused a marked and significant decrease in the ratio of reduced (GSH) to oxidized (GSSG) glutathione levels in cortex from treated animals $(p<0.05$, Figure 6(a)). Treatment with L. divaricata $(500$ or $1000 \mathrm{mg} / \mathrm{kg}$ ) completely restored the GSH/GSSG ratio in the cortex of treated animals $(p<0.05$, Figure 6(a)). In striatum the ratios in GSH/GSSG levels were not changed by the treatment with 3-NP and/or L. divaricata (Figure 6(b)).

Administration of $L$. divaricata, either alone or in combination with 3-NP, significantly decreased acetylcholinesterase activity $(p<0.05$, Figure $7(\mathrm{a}))$ in the cortex, being the $3-\mathrm{NP}$ 


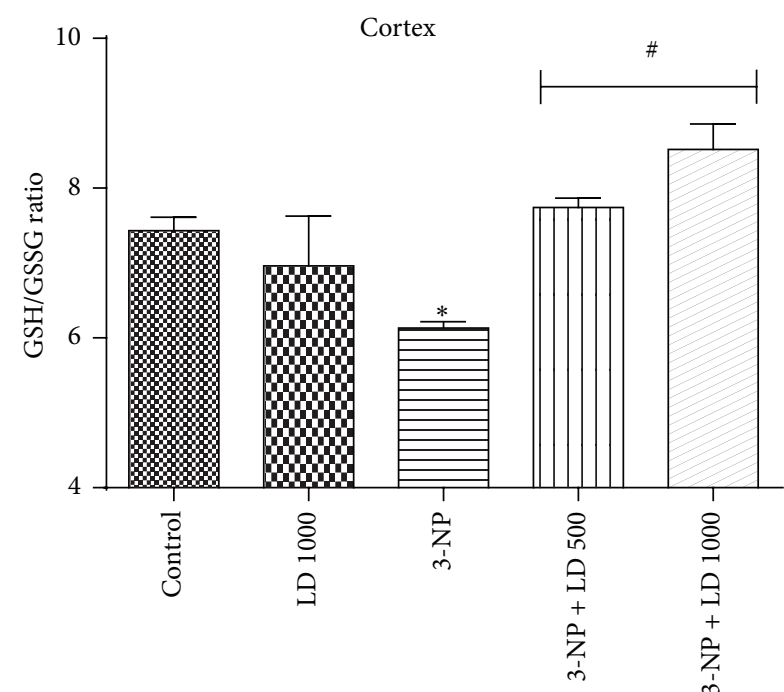

$(\mathrm{mg} / \mathrm{kg})$

(a)

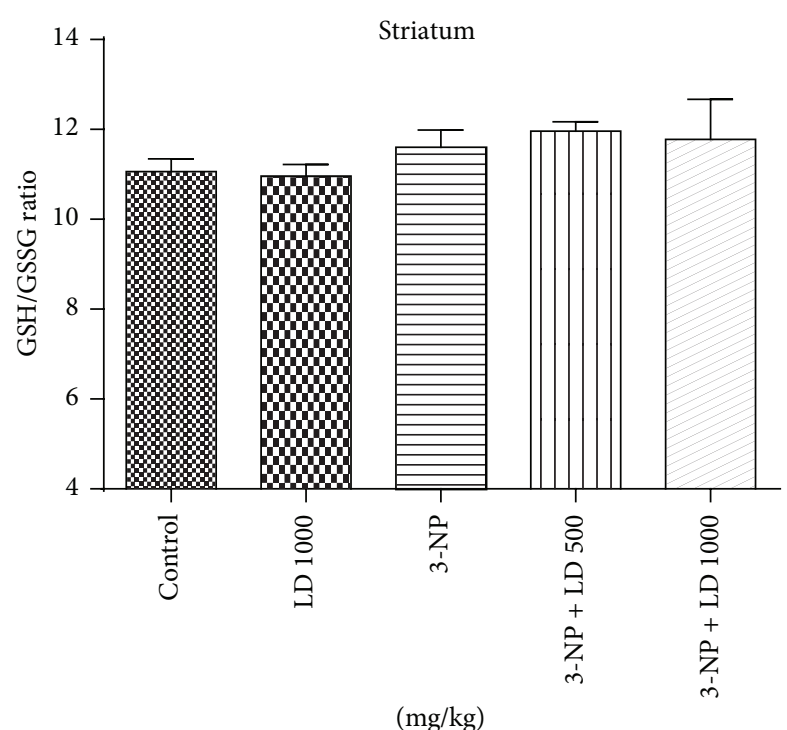

(b)

Figure 6: Effects of 3-NP (20 mg/kg, i.p., 3 days) and/or Luehea divaricata (LD) (500 and $1000 \mathrm{mg} / \mathrm{kg}$, by gavage, 10 days) on GSH/GSSG ratio in cortex (a) and striatum (b) of treated rats. Data are expressed as nmol GSH/mg of tissue. Each bar represents means \pm SEM $(n=5)$. * indicates statistic difference from control group and \# indicates statistic difference from 3-NP group by one-way ANOVA, followed by Newman Keuls post hoc test $(p<0.05)$.

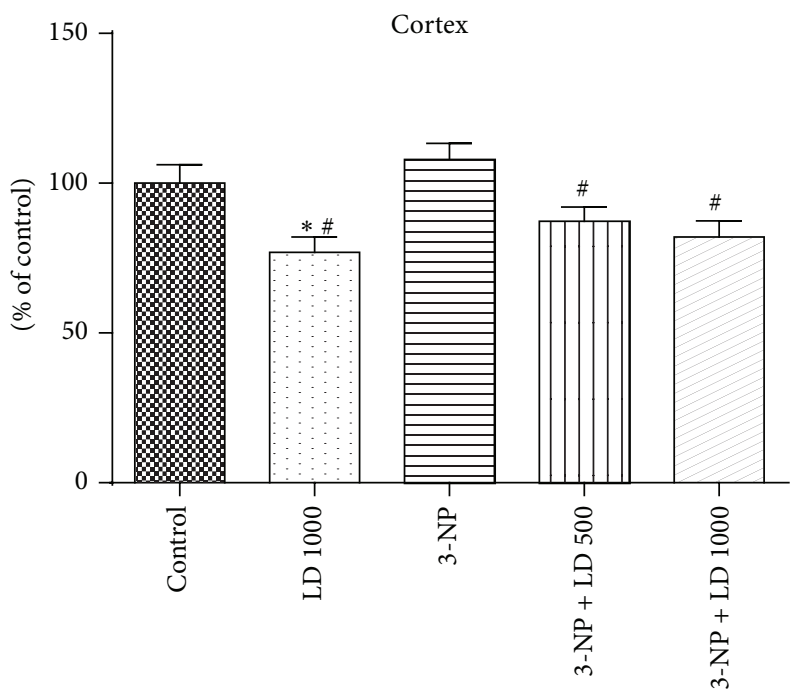

$(\mathrm{mg} / \mathrm{kg})$

(a)

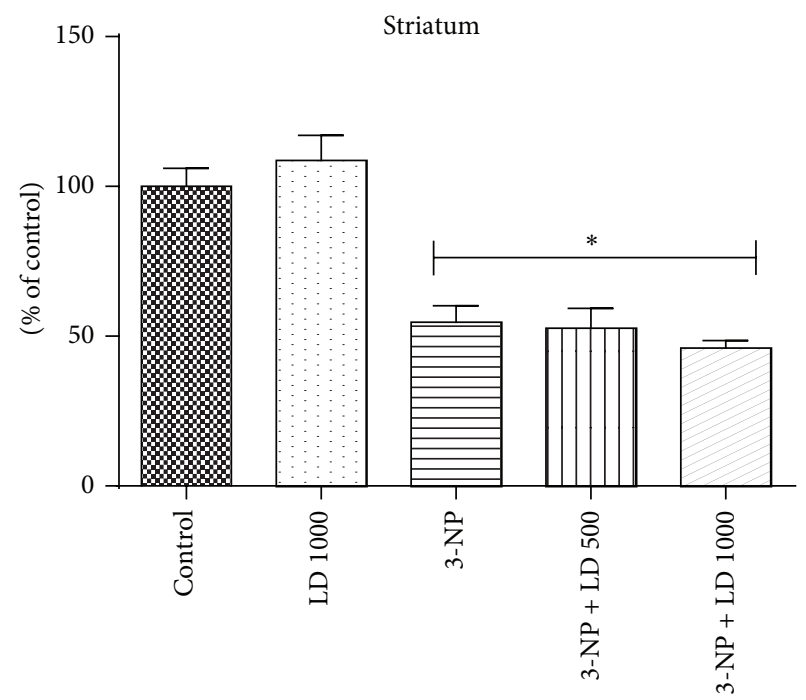

$(\mathrm{mg} / \mathrm{kg})$

(b)

FIGURE 7: Effects of 3-NP ( $20 \mathrm{mg} / \mathrm{kg}$, i.p., 3 days) and/or Luehea divaricata (LD) (500 and $1000 \mathrm{mg} / \mathrm{kg}$, by gavage, 10 days) on the acetylcholinesterase activity in cortex (a) and striatum (b) of treated rats. Data are expressed as \% of control. Each bar represents means \pm SEM $(n=5)$. * indicates statistic difference from control group and \# indicates statistic difference from 3-NP group by one-way ANOVA, followed by Newman Keuls post hoc test $(p<0.05)$.

without effect per se. However, the significant inhibition of activity of acetylcholinesterase activity in the striatum induced by 3-NP administration remained unchanged following $L$. divaricata treatment ( 500 or $1000 \mathrm{mg} / \mathrm{kg} ; p<0.05$, Figure $7(b)$ ).

\section{Discussion}

In the present study we tested the hypothesis that the aqueous extract of $L$. divaricata could prevent behavioral dysfunction and biochemical changes associated with an experimental 
model of HD induced by 3-NP administration in rats. Our results demonstrate that $L$. divaricata treatment protected against HD-associated behavioral deficits (improved locomotor and Rotarod performance) and attenuated biochemical changes associated with oxidative stress (decreased ROS formation in cortex and striatum, reduced lipid peroxidation, and restored GSH/GSSG ratio in cortex) induced by 3-NP.

Administration of $3-\mathrm{NP}$ in rats for 3 consecutive days caused significant motor dysfunction, characterized by decreased Rotarod and locomotor performance (Figures 2 and 3), suggesting that the effects of 3-NP administration mimic either juvenile onset or later stages of HD-like behaviors in humans $[5,40]$. These observations are supported by previous studies reporting that 3-NP administration induces motor system-associated behavioral deficits [3, 41]. Alterations in locomotor behavior may be due to the specific action of 3-NP, those regions of striatum and cortex which control body movement. Additionally, recent studies have indicated that abnormal behavioral symptoms in early HD patients are likely due to either cholinergic interneuron dysfunction in striatal circuits or direct cell loss within the lateral striatum, ventral pallidum, and entopeduncular nucleus [12, 42]. Previous reports have also confirmed 3-NP-induced lesions and oxidative damage in cortex and hippocampus, which may underlie deficits in motor performance $[43,44]$.

In the present study, pretreatment with $L$. divaricata significantly attenuated behavioral alterations (locomotor function as well as Rotarod performance) following 3-NP administration, suggesting that this compound may have novel therapeutic potential for the treatment of $\mathrm{HD}$ and related disorders (Figures 2 and 3). Previous studies support the use of antioxidant therapy to restore behavioral function and oxidative defense levels in 3-NP-treated animals [45, 46]. Using other plant species, a previous study [47] has reported that the root extract of Withania somnifera, characterized by high antioxidant content, reverses motor dysfunction caused by 3 -NP in rats. Treatment with antioxidants (polyphenols principally) has also been shown to protect in vivo against oxidative damage in a model of childhood-onset hydrocephalus in rats and it was found to be effective in improving learning and memory in senescence-accelerated mice including Alzheimer transgenic mice [48]. Thus, considering the presented results, the use of $L$. divaricata aqueous extract could be considered as a therapeutic strategy for the treatment and/or search for new drugs to treat/prevent human HD-like symptoms [13, 49]. However, despite no significant effect on locomotor activity, as assessed by open field test, treatment with $L$. divaricata was found to significantly decrease the latency to first fall in Rotarod test (Figure 3). This result was unexpected and without correlation with the other findings in our study; however, this result pointed out here deserves further attention in future studies with this plant in order to detect possible side effects of extract administration. Moreover, evidence suggests the involvement of oxidative stress in 3-NP neurotoxicity that includes a rapid increase in ROS production in neuronal cells [50] and hydroxyl free radicals, lipid peroxidation, and impaired antioxidant defense in the brain [51]. Accordingly, in this study we found a prooxidant effect of the 3-NP, which caused an increase in ROS production (Figure 4), as measured via DCF oxidation, and in lipid peroxidation (Figure 5), both in cortex and in striatum. These changes were significantly restored by pretreatment with $L$. divaricata extract, suggesting neuroprotective action due to its antioxidant effect. In fact, many studies indicate that the antioxidant activities of aqueous extracts of plants are benefits to the treatment of several diseases by the presence of numerous polyphenols, especially flavonoids [52, 53], which are much more effective than vitamins $\mathrm{C}$ and $\mathrm{E}$ in protecting cells from free radical damage [54]. In support to this notion, we found a lot of polyphenols in our extract (Figure 1 and Table 1) that could be active in our study, thus preventing against 3-NP-induced oxidative changes, and consequently against 3-NP-induced locomotors impairment.

Alterations in the antioxidant defense system were also observed in this study, as evidenced by a decrease in concentration of GSH/GSSG ratio in the cortex of 3-NPtreated rats (Figure 6(a)). GSH, a nonenzymatic antioxidant, plays an important role in reduction of ROS in brain. So, diminished GSH/GSSG levels have been linked with normal aging and neurodegenerative diseases [41, 55]. Moreover, treatment with $L$. divaricata significantly prevented 3-NPinduced GSH/GSSG consumption. Antioxidants have also been shown to protect the nervous system against variety of toxins $[13,56]$. A previously published report [57] demonstrated the efficacy of combined fish oil and quercetin to enhance GSH levels in 3-NP-treated animals.

Finally, we found that aqueous extract $L$. divaricata inhibited acetylcholinesterase activity, which could be due to specific compounds present in the aqueous extract. Previous studies have demonstrated that the compound rutin is an acetylcholinesterase (AChE) inhibitor in human plasma in vitro [58] suggesting that $L$. divaricata leaf extract may have anticholinesterase activity in vivo [22]. Extracts of $L$. divaricata may therefore be useful in treatments where acetylcholinesterase inhibition is employed, including neurological disorders such as $\mathrm{AD}$. Despite advances in the field, $\mathrm{AD}$ remains a devastating neurodegenerative disease with limited therapeutic options. One of the most useful approaches for the treatment of $\mathrm{AD}$ is based on the development of $\mathrm{AChE}$ inhibitors to attenuate disease-associated deficits of cerebral acetylcholine levels [59]. In addition to its anticholinesterase activity, L. divaricata extract may also be useful in $\mathrm{AD}$ due to the presence of the compound quercetin, which possesses antioxidant activity, enhances neuronal function, and decreases extracellular $\beta$-amyloidosis in addition to other beneficial effects on the nervous system including a protective effect on cognitive and emotional function in aged triple-transgenic AD mice $[60,61]$.

\section{Conclusion}

Our study demonstrates that the aqueous extract of $L$. divaricata is able to prevent oxidative and behavioral changes in an experimental model of HD induced by treatment with 3NP in rats. These results contribute to the body of knowledge concerning plant extracts and their various components that may be used as novel therapeutic strategies and suggest that this unique plant may be potentially efficacious in 
the prevention or treatment of neurodegenerative diseases, including HD.

\section{Conflict of Interests}

All authors report no conflict of interests.

\section{Acknowledgments}

This work was supported by grants from UNIPAMPA (Universidade Federal do Pampa), UFSM (Universidade Federal de Santa Maria), FAPERGS (Fundação de Amparo a Pesquisa do Estado do Rio Grande do Sul), CAPES (Coordenação de Aperfeiçoamento de Pessoal de Nível Superior), and CNPq (Conselho Nacional de Desenvolvimento Científico e Tecnológico).

\section{References}

[1] M.-C. Chiang, Y. Chern, and R.-N. Huang, "PPARgamma rescue of the mitochondrial dysfunction in Huntington's disease," Neurobiology of Disease, vol. 45, no. 1, pp. 322-328, 2012.

[2] C. A. Ross, E. H. Aylward, E. J. Wild et al., "Huntington disease: natural history, biomarkers and prospects for therapeutics," Nature Reviews Neurology, vol. 10, no. 4, pp. 204-216, 2014.

[3] J. Chakraborty, D. N. Nthenge-Ngumbau, U. Rajamma, and K. P. Mohanakumar, "Melatonin protects against behavioural dysfunctions and dendritic spine damage in 3-nitropropionic acid-induced rat model of Huntington's disease," Behavioural Brain Research, vol. 264, pp. 91-104, 2014.

[4] R. Sandhir and A. Mehrotra, "Quercetin supplementation is effective in improving mitochondrial dysfunctions induced by 3-nitropropionic acid: implications in Huntington's disease," Biochimica et Biophysica Acta: Molecular Basis of Disease, vol. 1832, no. 3, pp. 421-430, 2013.

[5] D. W. Weir, A. Sturrock, and B. R. Leavitt, "Development of biomarkers for Huntington's disease," The Lancet Neurology, vol. 10, no. 6, pp. 573-590, 2011.

[6] M.-C. Chiang, H.-M. Chen, Y.-H. Lee et al., "Dysregulation of $\mathrm{C} / \mathrm{EBP} \alpha$ by mutant Huntingtin causes the urea cycle deficiency in Huntington's disease," Human Molecular Genetics, vol. 16, no. 5, pp. 483-498, 2007.

[7] A. L. Orr, S. Li, C.-E. Wang et al., "N-terminal mutant huntingtin associates with mitochondria and impairs mitochondrial trafficking," The Journal of Neuroscience, vol. 28, no. 11, pp. 27832792, 2008.

[8] P. H. Reddy and U. P. Shirendeb, "Mutant huntingtin, abnormal mitochondrial dynamics, defective axonal transport of mitochondria, and selective synaptic degeneration in Huntington's disease," Biochimica et Biophysica Acta-Molecular Basis of Disease, vol. 1822, no. 2, pp. 101-110, 2012.

[9] W. Song, J. Chen, A. Petrilli et al., "Mutant huntingtin binds the mitochondrial fission GTPase dynamin-related protein-1 and increases its enzymatic activity," Nature Medicine, vol. 17, no. 3, pp. 377-382, 2011.

[10] A. C. Ludolph, F. He, P. S. Spencer, J. Hammerstad, and M. Sabri, "3-nitropropionic acid-exogenous animal neurotoxin and possible human striatal toxin," Canadian Journal of Neurological Sciences, vol. 18, no. 4, pp. 492-498, 1991.

[11] I. Túnez, I. Tasset, V. P.-D. La Cruz, and A. Santamaría, "3nitropropionic acid as a tool to study the mechanisms involved in huntington's disease: past, present and future," Molecules, vol. 15, no. 2, pp. 878-916, 2010.

[12] E. Brouillet, "The 3-NP model of striatal neurodegeneration," Current Protocols in Neuroscience, vol. 67, pp. 9.48.1-9.48.14, 2014.

[13] D. Colle, D. B. Santos, E. L. G. Moreira et al., "Probucol increases striatal glutathione peroxidase activity and protects against 3-nitropropionic acid-induced pro-oxidative damage in rats," PLoS ONE, vol. 8, no. 6, Article ID e67658, 2013.

[14] A. Johri, A. Chandra, and M. F. Beal, "PGC- $1 \alpha$, mitochondrial dysfunction, and Huntington's disease," Free Radical Biology and Medicine, vol. 62, pp. 37-46, 2013.

[15] S. R. Mirandola, D. R. Melo, Â. Saito, and R. F. Castilho, “3nitropropionic acid-induced mitochondrial permeability transition: comparative study of mitochondria from different tissues and brain regions," Journal of Neuroscience Research, vol. 88, no. 3, pp. 630-639, 2010.

[16] S. Thangarajan, A. Deivasigamani, S. S. Natarajan, P. Krishnan, and S. K. Mohanan, "Neuroprotective activity of L-theanine on 3-nitropropionic acid-induced neurotoxicity in rat striatum," International Journal of Neuroscience, vol. 124, no. 9, pp. 673684, 2014.

[17] Y.-J. Wang, P. Thomas, J.-H. Zhong et al., "Consumption of grape seed extract prevents amyloid- $\beta$ deposition and attenuates inflammation in brain of an alzheimer's disease mouse," Neurotoxicity Research, vol. 15, no. 1, pp. 3-14, 2009.

[18] T. M. Tsang, J. N. Haselden, and E. Holmes, "Metabonomic characterization of the 3-nitropropionic acid rat model of huntington's disease," Neurochemical Research, vol. 34, no. 7, pp. 1261-1271, 2009.

[19] M. Damiano, E. Diguet, C. Malgorn et al., "A role of mitochondrial complex II defects in genetic models of Huntington's disease expressing N-terminal fragments of mutant huntingtin," Human Molecular Genetics, vol. 22, no. 19, pp. 3869-3882, 2013.

[20] M. B. Khan, M. M. Khan, A. Khan et al., "Naringenin ameliorates Alzheimer's disease (AD)-type neurodegeneration with cognitive impairment (AD-TNDCI) caused by the intracerebroventricular-streptozotocin in rat model," Neurochemistry International, vol. 61, no. 7, pp. 1081-1093, 2012.

[21] B. Uttara, A. V. Singh, P. Zamboni, and R. T. Mahajan, "Oxidative stress and neurodegenerative diseases: a review of upstream and downstream antioxidant therapeutic options," Current Neuropharmacology, vol. 7, no. 1, pp. 65-74, 2009.

[22] L. P. Arantes, D. Colle, M. L. Machado et al., "Luehea divaricata Mart. anticholinesterase and antioxidant activity in a Caenorhabditis elegans model system," Industrial Crops and Products, vol. 62, pp. 265-271, 2014.

[23] G. P. Amaral, N. R. de Carvalho, R. P. Barcelos et al., "Protective action of ethanolic extract of Rosmarinus officinalis L. in gastric ulcer prevention induced by ethanol in rats," Food and Chemical Toxicology, vol. 55, pp. 48-55, 2013.

[24] N. Babbar, H. S. Oberoi, and S. K. Sandhu, "Therapeutic and nutraceutical potential of bioactive compounds extracted from fruit residues," Critical Reviews in Food Science and Nutrition, vol. 55, no. 3, pp. 319-337, 2015.

[25] T. A. Loomis, A. M. Font, and N. C. Cortes, Fundamentos de Toxicología, Acribia, 1982.

[26] H. Lorenzi and I. P. D. E. D. Flora, Arvores Brasileiras: Manual de Identificação e Cultivo de Plantas Arbóreas Nativas do Brasil, Instituto Plantarum de Estudos da Flora, 1998. 
[27] A. E. Bighetti, M. A. Antônio, A. Possenti, M. A. Foglio, M. G. Siqueira, and J. E. de Carvalho, "Efeitos da administração aguda e subcrônica da Luehea divaricata Martus et Zuccarini," LectaUSF, vol. 22, no. 1-2, pp. 53-58, 2004.

[28] J. C. A. Tanaka, C. C. da Silva, B. P. D. Filho, C. V. Nakamura, J. E. de Carvalho, and M. A. Foglio, "Constituintes químicos de Luehea divaricata Mart. (Tiliaceae)," Química Nova, vol. 28, no. 5, pp. 834-837, 2005.

[29] V. M. Vargas, R. R. Guidobono, and J. A. Henriques, "Genotoxicity of plant extracts," Memorias do Instituto Oswaldo Cruz, vol. 86, supplement 2, pp. 67-70, 1991.

[30] L. P. Felício, E. M. Silva, V. Ribeiro et al., "Mutagenic potential and modulatory effects of the medicinal plant Luehea divaricata (Malvaceae) in somatic cells of Drosophila melanogaster: SMART/wing," Genetics and Molecular Research, vol. 10, no. 1, pp. 16-24, 2011.

[31] B. G. Marinho, L. S. M. Miranda, J. Da S. Costa et al., "The antinociceptive properties of the novel compound $( \pm)$-trans4-hydroxy-6-propyl-1-oxocyclohexan-2-one in acute pain in mice," Behavioural Pharmacology, vol. 24, no. 1, pp. 10-19, 2013.

[32] F. Sofi, C. Macchi, R. Abbate, G. F. Gensini, and A. Casini, "Mediterranean diet and health," BioFactors, vol. 39, no. 4, pp. 335-342, 2013.

[33] V. M. B. Filho, E. P. Waczuk, J. P. Kamdem et al., "Phytochemical constituents, antioxidant activity, cytotoxicity and osmotic fragility effects of Caju (Anacardium microcarpum)," Industrial Crops and Products, vol. 55, pp. 280-288, 2014.

[34] M. E. Burger, R. Fachinetto, G. Zeni, and J. B. T. Rocha, "Ebselen attenuates haloperidol-induced orofacial dyskinesia and oxidative stress in rat brain," Pharmacology Biochemistry and Behavior, vol. 81, no. 3, pp. 608-615, 2005.

[35] A. R. S. Santos, R. O. P. De Campos, O. G. Miguel, V. CechinelFilho, R. A. Yunes, and J. B. Calixto, "The involvement of $\mathrm{K}^{+}$ channels and $\mathrm{G}_{\mathrm{i} / \mathrm{o}}$ protein in the antinociceptive action of the gallic acid ethyl ester," European Journal of Pharmacology, vol. 379, no. 1, pp. 7-17, 1999.

[36] O. Myhre, J. M. Andersen, H. Aarnes, and F. Fonnum, "Evaluation of the probes $2^{\prime}, 7^{\prime}$-dichlorofluorescin diacetate, luminol, and lucigenin as indicators of reactive species formation," Biochemical Pharmacology, vol. 65, no. 10, pp. 1575-1582, 2003.

[37] H. Ohkawa, N. Ohishi, and K. Yagi, "Assay for lipid peroxides in animal tissues by thiobarbituric acid reaction," Analytical Biochemistry, vol. 95, no. 2, pp. 351-358, 1979.

[38] P. J. Hissin and R. Hilf, "A fluorometric method for determination of oxidized and reduced glutathione in tissues," Analytical Biochemistry, vol. 74, no. 1, pp. 214-226, 1976.

[39] O. H. Lowr, N. J. Rosebrough, A. L. Farr, and R. J. Randall, "Protein measurement with the Folin phenol reagent," The Journal of Biological Chemistry, vol. 193, no. 1, pp. 265-275, 1951.

[40] A. Dhir, K. K. Akula, and S. K. Kulkarni, “Tiagabine, a GABA uptake inhibitor, attenuates 3-nitropropionic acid-induced alterations in various behavioral and biochemical parameters in rats," Progress in Neuro-Psychopharmacology and Biological Psychiatry, vol. 32, no. 3, pp. 835-843, 2008.

[41] D. K. Bhateja, D. K. Dhull, A. Gill et al., "Peroxisome proliferator-activated receptor- $\alpha$ activation attenuates 3-nitropropionic acid induced behavioral and biochemical alterations in rats: possible neuroprotective mechanisms," European Journal of Pharmacology, vol. 674, no. 1, pp. 33-43, 2011.

[42] I. Han, Y. You, J. H. Kordower, S. T. Brady, and G. A. Morfini, "Differential vulnerability of neurons in Huntington's disease: the role of cell type-specific features," Journal of Neurochemistry, vol. 113, no. 5, pp. 1073-1091, 2010.

[43] P. Kumar, H. Kalonia, and A. Kumar, "Possible GABAergic mechanism in the neuroprotective effect of gabapentin and lamotrigine against 3-nitropropionic acid induced neurotoxicity," European Journal of Pharmacology, vol. 674, no. 2-3, pp. 265274, 2012.

[44] E. A. Wilhelm, C. F. Bortolatto, C. R. Jesse, and C. Luchese, "Ebselen protects against behavioral and biochemical toxicities induced by 3-nitropropionic acid in rats: correlations between motor coordination, reactive species levels, and succinate dehydrogenase activity," Biological Trace Element Research, vol. 162, no. 1-3, pp. 200-210, 2014.

[45] C. Jadiswami, H. M. Megha, S. B. Dhadde et al., "Piroxicam attenuates 3-nitropropionic acid-induced brain oxidative stress and behavioral alteration in mice," Toxicology Mechanisms and Methods, vol. 24, no. 9, pp. 672-678, 2014.

[46] E. T. Menze, A. Esmat, M. G. Tadros, A. B. Abdel-Naim, and A. E. Khalifa, "Genistein improves 3-NPA-induced memory impairment in ovariectomized rats: impact of its antioxidant, anti-inflammatory and acetylcholinesterase modulatory properties," PLoS ONE, vol. 10, no. 2, Article ID e0117223, 2015.

[47] P. Kumar and A. Kumar, "Possible neuroprotective effect of withania somnifera root extract against 3-nitropropionic acidinduced behavioral, biochemical, and mitochondrial dysfunction in an animal model of huntington's disease," Journal of Medicinal Food, vol. 12, no. 3, pp. 591-600, 2009.

[48] K. Rezai-Zadeh, D. Shytle, N. Sun et al., "Green tea epigallocatechin-3-gallate (EGCG) modulates amyloid precursor protein cleavage and reduces cerebral amyloidosis in Alzheimer transgenic mice," The Journal of Neuroscience, vol. 25, no. 38, pp. 8807-8814, 2005.

[49] P. Kumar and A. Kumar, "Possible role of sertraline against 3-nitropropionic acid induced behavioral, oxidative stress and mitochondrial dysfunctions in rat brain," Progress in NeuroPsychopharmacology and Biological Psychiatry, vol. 33, no. 1, pp. $100-108,2009$.

[50] A. Bueno-Nava, R. Gonzalez-Pina, A. Alfaro-Rodriguez et al., "Recovery of motor deficit, cerebellar serotonin and lipid peroxidation levels in the cortex of injured rats," Neurochemical Research, vol. 35, no. 10, pp. 1538-1545, 2010.

[51] R. Sandhir, A. Mehrotra, and S. S. Kamboj, "Lycopene prevents 3-nitropropionic acid-induced mitochondrial oxidative stress and dysfunctions in nervous system," Neurochemistry International, vol. 57, no. 5, pp. 579-587, 2010.

[52] H. Javed, M. M. Khan, A. Ahmad et al., "Rutin prevents cognitive impairments by ameliorating oxidative stress and neuroinflammation in rat model of sporadic dementia of Alzheimer type," Neuroscience, vol. 210, pp. 340-352, 2012.

[53] M. Nassiri-Asl, T. Naserpour Farivar, E. Abbasi et al., "Effects of rutin on oxidative stress in mice with kainic acid-induced seizure," Journal of integrative medicine, vol. 11, no. 5, pp. 337342, 2013.

[54] R. da Silva Nunes, V. F. S. Kahl, M. da Silva Sarmento et al., "Antigenotoxicity and antioxidant activity of Acerola fruit (Malpighia glabra L.) at two stages of ripeness," Plant Foods for Human Nutrition, vol. 66, no. 2, pp. 129-135, 2011.

[55] K. Gopinath, D. Prakash, and G. Sudhandiran, "Neuroprotective effect of naringin, a dietary flavonoid against 3Nitropropionic acid-induced neuronal apoptosis," Neurochemistry International, vol. 59, no. 7, pp. 1066-1073, 2011. 
[56] E. de Almeida Jackix, E. B. Monteiro, H. F. Raposo, E. C. Vanzela, and J. Amaya-Farfán, "Taioba (Xanthosoma sagittifolium) leaves: nutrient composition and physiological effects on healthy rats," Journal of Food Science, vol. 78, no. 12, pp. H1929-H1934, 2013.

[57] D. K. M. Joseph and Muralidhara, "Neuroprotective efficacy of a combination of fish oil and ferulic acid against 3nitropropionic acid-induced oxidative stress and neurotoxicity in rats: behavioural and biochemical evidencel," Applied Physiology, Nutrition and Metabolism, vol. 39, no. 4, pp. 487-496, 2014.

[58] M. Katalinic, G. Rusak, J. Domaćinović Barović et al., "Structural aspects of flavonoids as inhibitors of human butyrylcholinesterase," European Journal of Medicinal Chemistry, vol. 45, no. 1, pp. 186-192, 2010.

[59] C. Ballard, S. Gauthier, A. Corbett, C. Brayne, D. Aarsland, and E. Jones, "Alzheimer's disease," The Lancet, vol. 377, no. 9770, pp. 1019-1031, 2011.

[60] A. M. Sabogal-Guáqueta, J. I. Muñoz-Manco, J. R. RamírezPineda, M. Lamprea-Rodriguez, E. Osorio, and G. P. CardonaGómez, "The flavonoid quercetin ameliorates Alzheimer's disease pathology and protects cognitive and emotional function in aged triple transgenic Alzheimer's disease model mice," Neuropharmacology, vol. 93, pp. 134-145, 2015.

[61] C.-M. Liu, G.-H. Zheng, C. Cheng, and J.-M. Sun, "Quercetin protects mouse brain against lead-induced neurotoxicity," Journal of Agricultural and Food Chemistry, vol. 61, no. 31, pp. 76307635, 2013. 


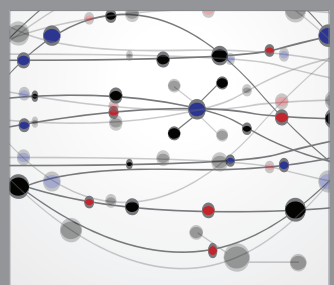

The Scientific World Journal
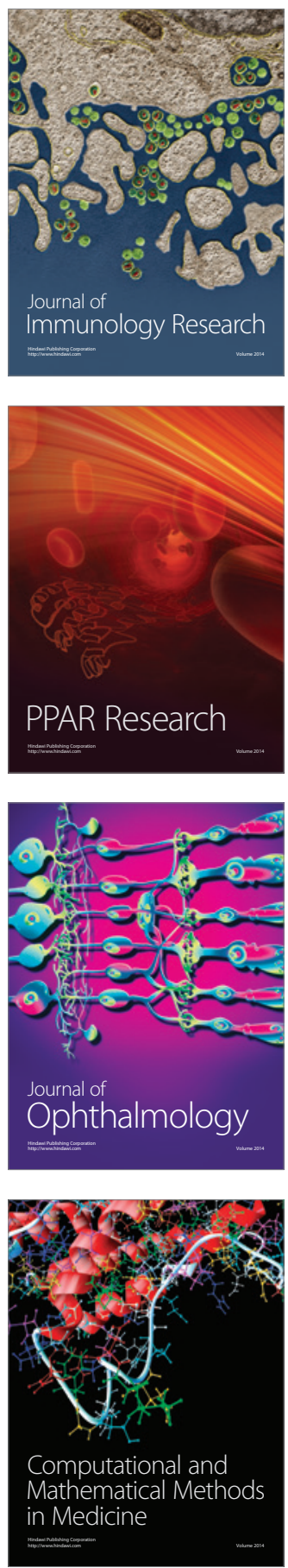

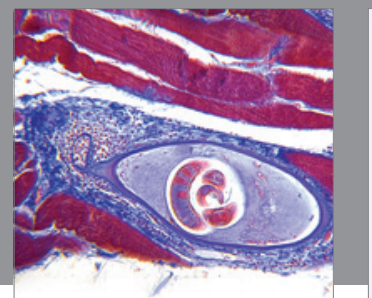

Gastroenterology

Research and Practice
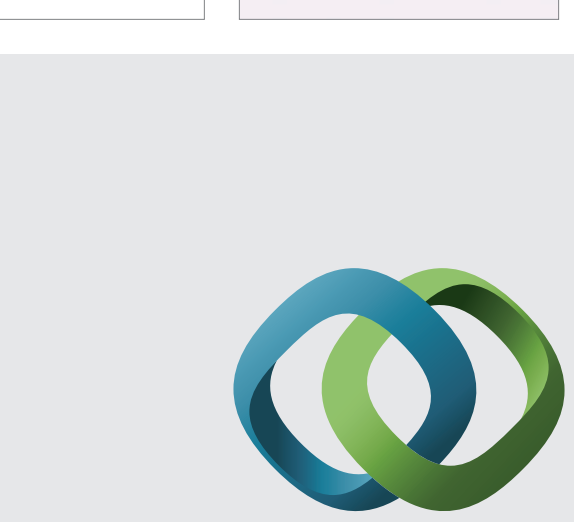

\section{Hindawi}

Submit your manuscripts at

http://www.hindawi.com
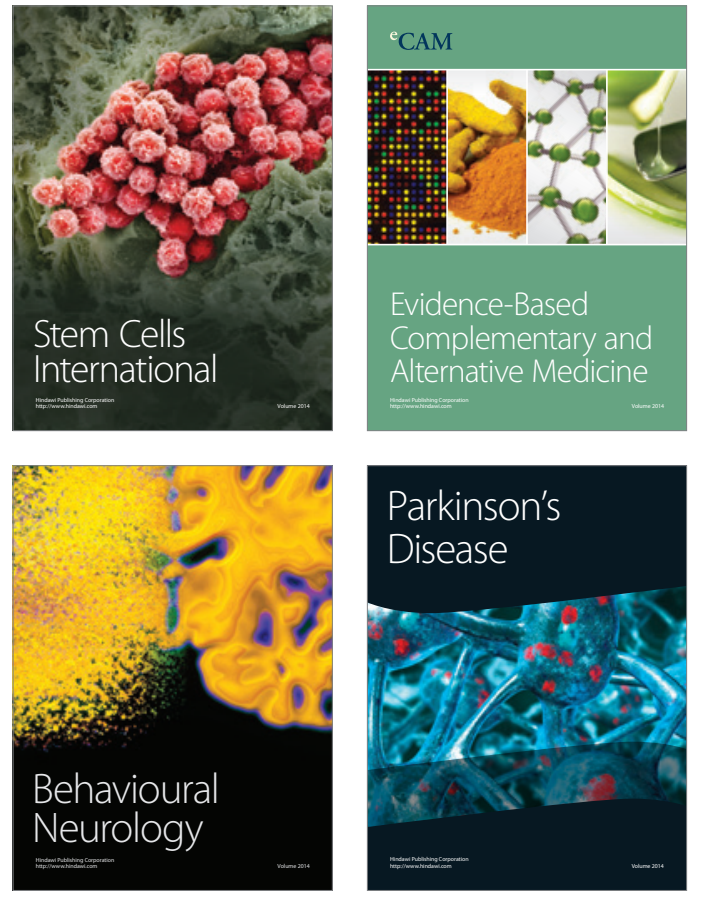
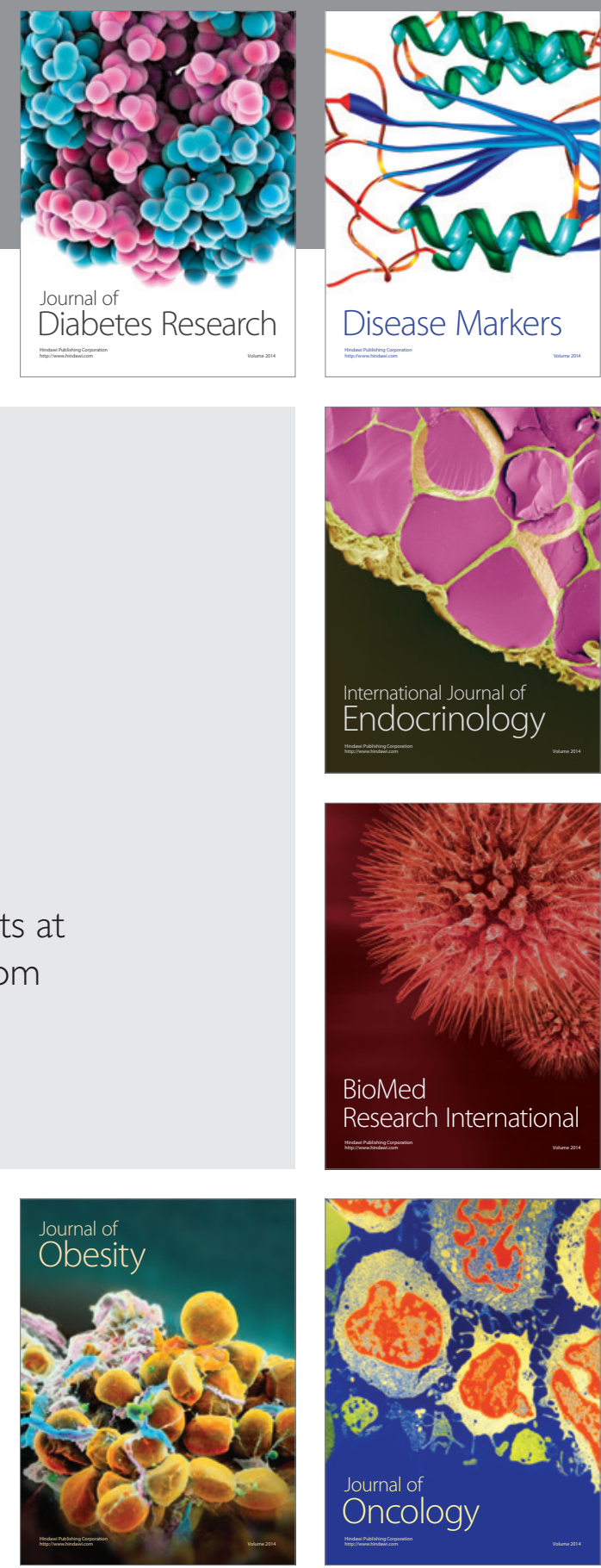

Disease Markers
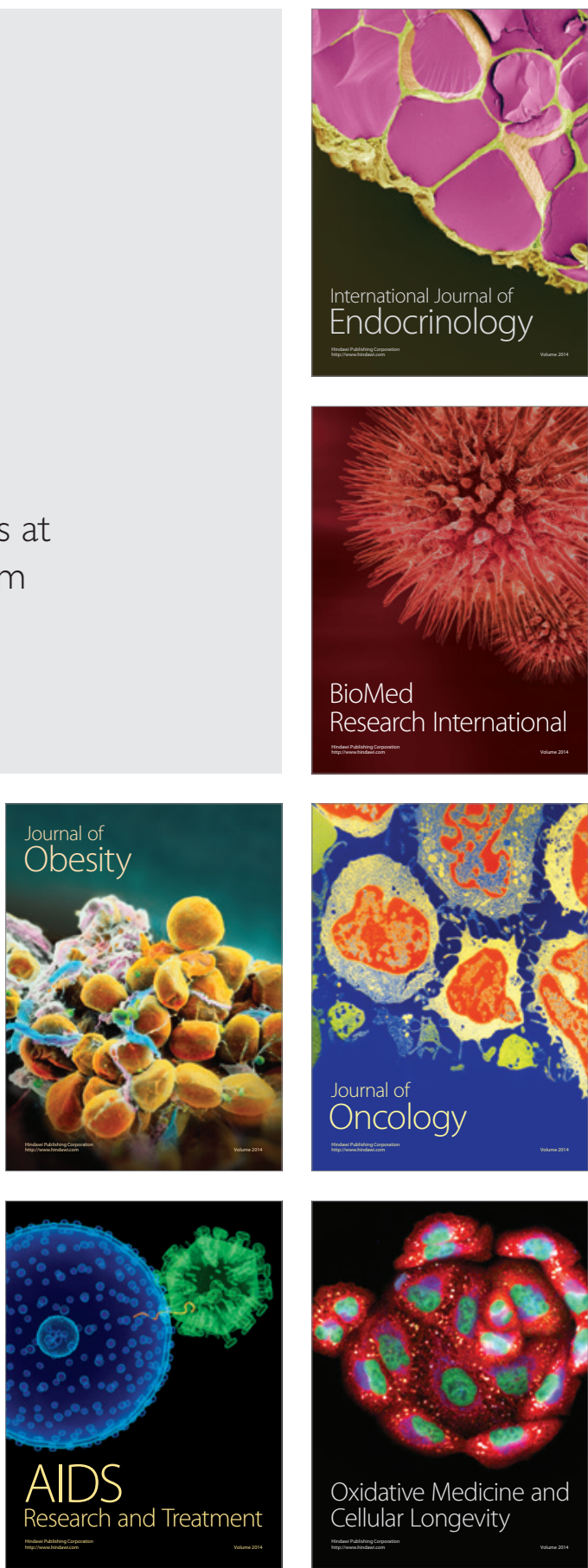